\title{
Sociocultural contexts of attempting suicide among Iranian youth: a qualitative study
}

M. Keyvanara ${ }^{7}$ and A. Haghshenas ${ }^{7}$

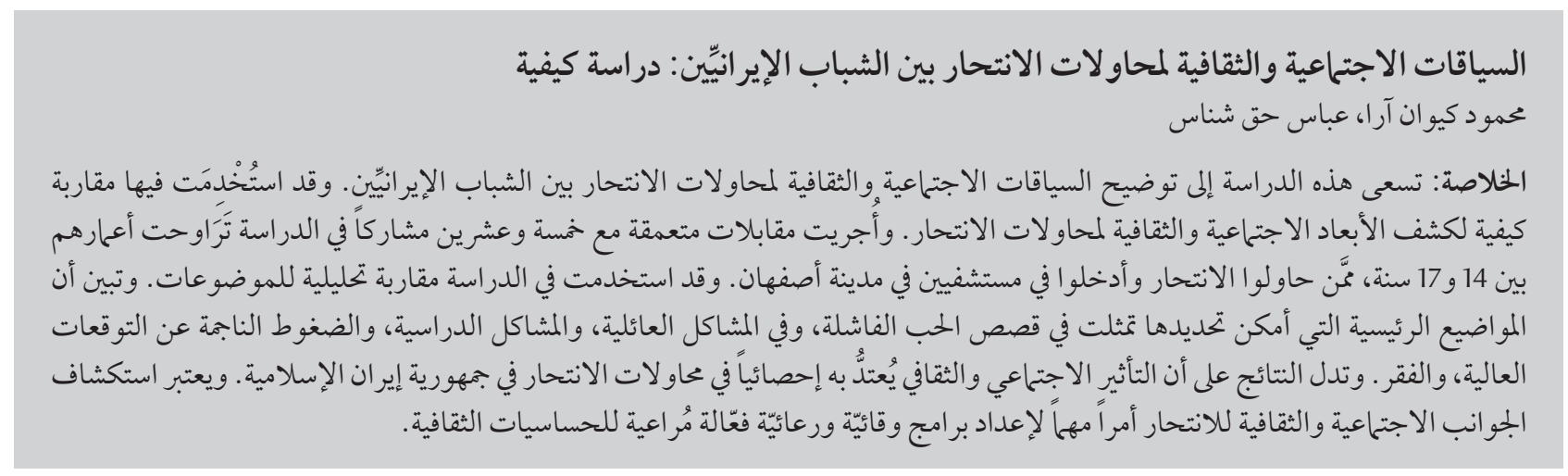

ABSTRACT This paper seeks to illuminate the sociocultural contexts of attempting suicide among Iranian youth. A qualitative approach was employed to uncover the social and cultural dimensions of attempting suicide. In-depth interviews were conducted with 25 participants aged 14-17 years who attempted suicide and were admitted to 2 of the hospitals in Isfahan. A thematic analysis approach was employed. The main themes identified were failure in love, family problems, study, pressure of high expectations and poverty. The findings suggest significant sociocultural influence on attempting suicide in the Islamic Republic of Iran. Exploring sociocultural aspects of suicide is critical in providing effective and culturally-sensitive suicide prevention and care programmes.

\section{Contextes socioculturels des tentatives de suicide chez les jeunes Iraniens : une étude qualitative}

RÉSUMÉ Le présent article met en lumière les contextes socioculturels des tentatives de suicide chez les jeunes Iraniens. Une méthode qualitative a été utilisée pour déterminer les dimensions sociales et culturelles des tentatives de suicide. Des entretiens approfondis ont été réalisés avec 25 participants âgés de 14 à 17 ans et admis dans deux hôpitaux d'Ispahan après une tentative de suicide. L'analyse a été réalisée selon une approche thématique. Les principaux thèmes identifiés étaient une rupture sentimentale, les problèmes familiaux, l'échec scolaire, des attentes élevées générant une pression et la pauvreté. Les résultats laissent entrevoir le poids d’une influence socioculturelle importante sur les tentatives de suicide en République islamique d'Iran. L'étude des aspects socioculturels du suicide est essentielle afin d'offrir des programmes de prévention du suicide et de soins efficaces et adaptés aux sensibilités culturelles.

${ }^{7}$ Faculty of Health Management and Medical Informatics, Social Sciences and Health Research Centre, Isfahan University of Medical Sciences, Isfahan, Islamic Republic of Iran (Correspondence to M. Keyvanara: Keyvanara@mng.mui.ac.ir).

Received: 20/08/09; accepted: 21/12/09 


\section{Introduction}

Suicide and attempted suicide are complex behaviours with multiple risk factors involved. It has been argued that suicidal behaviour falls along a continuum ranging from thoughts of suicide to suicide behaviour (e.g. planning, method identification) to suicide attempts, and in some cases to suicide [1].

Suicide attempt severely impacts on individuals and society in terms of physical and mental health, long-term disability and death as well as quality of life $[2,3]$.

The rate of suicide among youth has been increasing. This escalation in suicide rates among young individuals in developed countries began around 1980 and has continued to rise [3]; they are currently the high risk group in one third of all developed and developing countries [4]. Similar studies in the Islamic Republic of Iran as well as in some other Islamic countries have also highlighted the particular risk related to attempting suicide [5].

It has been shown that attempting suicide is prevalent in the age group 15-24 years in the Islamic Republic of Iran, especially among women [6]. The main methods used are reported to be overdosing and self-burning (selfimmolation) [7,8]. In 1999 and 2000, 895 cases of deliberate overdose and 97 cases of self-immolation were admitted to hospital in Isfahan, the second largest city in the country, most of these aged 10-29 years [9].

It is argued that suicide may be seen as an internal psychological phenomenon, as a social phenomenon [10] and as a phenomenon related to other psychiatric disorders and genetic problems [11]. It results from factors related to biological, psychological and social contexts. Suicide has different meaning in different cultures and settings. Social and cultural factors such as marital status, isolation, religion [10], age, unemployment $[12,13]$ social class [14], race and how suicide and its consequences are viewed, valued and interpreted by various cultures are all of consequence. For example, a great number of suicides in the Islamic Republic of Iran are not reported since it is considered a great sin in Islam, the majority religion [15].

Since suicide is defined by many factors and a deep understanding of these is necessary for suggesting avenues for prevention and rehabilitation of those attempting suicide. Therefore, a qualitative approach was selected for this study to provide a deep and broad understanding of this complex, multifaceted phenomenon. Qualitative methods can explore the meanings of suicide $[16,17]$ and the intentions of actors [18] within the sociocultural contexts of suicide. Since suicide among youth poses a major challenge for health care currently in our country, this study focuses on the sociocultural context of suicide among youth

\section{Methods}

We employed in-depth interview techniques with young people aged 14-17 years who attempted suicide in order to obtain descriptions and meanings of the interviewee's life events. An unstructured interview approach was employed to let participants to raise their own views and perceptions, to uncover underlying problems, issues and meanings as well as offering an apparently "deeper" picture than the variable-based correlations of quantitative studies [19]. The interview guide included demographic questions such as sex, age, marital status, geographic location, medical history, experiences and problems.

Study participants were recruited from patients who attempted suicide either through poisoning or self-burning, and who had been admitted to the toxicology ward or burn hospitals in Isfahan. Participants were enrolled through a purposive sampling strategy [20] to ensure a variety of views and perspectives.
The research team identified individuals aged 14-17 years who had recently attempted suicide and invited them to participate. Volunteers were selected who declared themselves willing and who were capable of talking about their experiences. The participants' medical reports were checked to ensure they were not suffering from acute psychosis, intense depression or bipolar disorder. Patients who had anti-social behaviour and those who were not able to complete the interview process were excluded

A total of 17 self-poisoned and 8 selfburned patients were interviewed. The interview process was carried out from March 2006 to October 2007. Data collection continued until saturation was achieved, i.e. until no new conceptual patterns were emerging [21]. Consent was obtained from all participants. The anonymity of the participants was preserved.

The interview time ranged from 15 to 50 minutes. All interviews were taperecorded and were transcribed verbatim by researchers. Data were stored in a secure cabinet and password protected computer file. Thematic analysis was used to make sense of qualitative data. During analysis, transcriptions were read iteratively and frequently in order to get familiar with the text and develop the "theme" out of the text [22].

\section{Results}

All interviewees were single; 16 were female and 9 were male. The commonest methods used to attempt suicide include overdose, by 15 interviewees; self-burning by 8 interviewees and poison by 2 interviewees.

Following analysis, data were categorized into 5 themes: expression of despair, failure in love, family problems, pressure of high expectations, and poverty. These themes are explained and explored in detail. 


\section{Expression of despair in participants}

Participants expressed feelings of depression and despair in various ways. Many expressed feeling of worthlessness, loneliness, sorrow and sadness as well as sleep disturbances.

A common complaint was Narahati: not being comfortable; upset or in distress. This term encompasses a wide rage of psycho-emotional states such as being anxious, depressed or upset.

Other common terms used by participants to express their emotional status were Assabani, Assabi, Feshar-e assabi and Assabe-e khord. These terms originate from the word A'sab (literary meaning nerve) and explains an uncontrollable anger, being irritable, agitated, high temper, nervous, psychic pressure, and loss of self-control in social interactions. A 16-year-old girl for instance says: I was so Assabani [angry] that I took all tablets (Interviewee 11).

Another participant also lost control during an impulse: I am very regretful now and I was very Assabani, and I cannot understand what I did. They created a sense of Assab-e khord for me (Interviewee 5).

Also the youths expressed feelings of $\mathrm{Na}$ 'omidi [hopelessness and futility; loss of hope]. For example one girl strongly expressed Na'omidi as her "life is finished" and she had "lost her future". I felt I have lost my dreams. Everything became dark and my future was also dark. ... It seemed I had lost my future and my life. I felt everything in my life is finished. There were no desires for me. I couldn't believe that my life was going to be damaged. It seemed my life was burned and passed off. I couldn't sleep last night and... (Interviewee 5).

Some participants explained their emotions as being Zood-ranj [irritable] or Hassas [sensitive] in reaction to certain circumstances: I am Assabani, Zood-ranj and Hassas person. My mother behaves in a bad way with me all the time and everywhere. Whenever she does this I become really Narahat [sad], Assabani [nervous] and have a feeling of annoyance (Interviewee 6).

It was clear that such psycho-emotional problems were shared by many participants, which could have played an important role in attempting suicide. The causes of these problems were explored and explained.

\section{Failure in love}

Some participants expressed difficulties in love as their main reason for attempting suicide. Two girls and 2 boys reported overdosing to attempt suicide due to failure in love. One girl, for example, says: I have fallen in love with a 19-year-old boy. I love him extremely. Yesterday he told me he is going overseas, it was so hard, it was really Narahati [sad], I don't know what I can do ... . My mother and my sister knew about my love but my father didn't (interviewee 5).

The other young girl resonates similar issues: I fell in love with a 19-year-old boy; we found each other in a party... I love him but we had to cover our love because of our families ... My father did not know about him (my love) but my mother was suspicious about our relationship (Interviewee 11).

In addition to interpersonal reasons, social stigma regarding outside marriage relationships appeared as one of the main causes of troubles in love. Both girls were trying to keep their relationship with their boyfriends secret because of strong family opposition. The shame of exposing the relationship was so unbearable for one of the girls that it lead her to attempting suicide.

The young participants not only had many obstacles with love and relationship outside marriage but also expressed frustration in search for love within socially acceptable norms. Issues such as parental consent, jobs, money, education and social class differences and "traditional customs" of marriage played important roles in marriage. A 17-yearold boy, for instance, a hairdresser, fell in love with a girl and decided to marry her.
He faced strong opposition, however, from the girl's father, who was quite inflexible in settling the "marriage portion" or Mahr [the part of the marriage portion settled upon the wife, which is paid in cash]. Having a high marriage portion for girls is considered to be socially prestigious: When my family and I went to their house to propose marriage and, during the procedure of wedlock, my father fell in discussion and then quarrelled with my beloved's uncle on the marriage portion. Finally we had to leave their home. I became so Narahati [sad] for a few months. Last week, again we went to their house. This time they started quarrelling and did not agree to our marriage (Interviewee 23).

\section{Family issues}

Family issues emerged one of the main themes related to attempting suicide in the youths. This included the subthemes of family disorder, child-parent friction and sibling friction.

\section{Family disorder}

This refers to family problems such as single parents, divorce, drug abuse, parental conflict and having a stepmother or stepfather. Four participants expressed concerns regarding family conflicts. For example, in a lengthy account, a young girl showed how her parents' divorce and disagreements led her to leave school, depression and finally attempting suicide. The divorce, her depressive disorder, and her suicide attempts seemed to be interrelated, so she resorted to marriage as a way out of a "bad situation": I had to go to my father's home for a few weeks and then go back to my mother's again; it was horrible and intolerable (Interviewee 20).

She thought marriage could bring her an independent life but her mother, who had responsibility for her at the time, believed she .... was too young for marriage, ....but for me marriage was an opportunity to get out of a bad situation (Interviewee 20). However, from this girl's point of view, her mother's opposition to her marriage was mainly a reflection 
of her own marriage experiences. Her father also opposed her marriage - for no reason. Opposition of both parents to her marriage as the only way of getting out of such a miserable situation left her with no choice except for attempting suicide: I preferred to live with my mother permanently. But my identity card was left in my father's home as I forgot to bring it with me. Several times I asked my father to give it back but he refused to return it. I needed it because I was going to get married and I needed it for recording the official recognition of marriage. I complained to my uncle about my father. I told him that my father did not support us financially, so he should not bother us and should leave us alone (Interviewee 20).

Similar issues were raised by 2 young girls providing a partial explanation for their suicide attempts. One of them says: Last night my parents fell into a quarrel again. I have a widowed sister, she doesn't live with us ... she is living with my uncle's family... (Interviewee 11).

\section{Child-parent conflicts}

Another subtheme identified as being potentially responsible for youth attempting suicide was conflict with their parents. Youth willingness to an independent life and parents efforts to controlandimposelimitations appeared as one of the reasons for child-parent conflict. This has led some youth towards depression and suicide attempts, as in this girl's excerpt: My mother usually follows me when I go out of my home. She checks the time of my coming and going out. I can't do any make-up and dressing. Ineed a bit of freedom. My mother is worried about my relationship with my love (interviewee 11). She saw her mother as the main obstacle in her relationship with her love. She had frequent arguments and quarrels with her mother.

Parental control and limitations also extended to boys for issues such as education, future life plan and also avoiding trouble. A 16-year-old boy believed his mother did not respect his autonomy; this resulted in friction between them and he overdosed on tablets. He says: My mother usually interferes in the details of my duties (my daily life). She has the last say about my friends, my fun and everything else (Interviewee 13). His mother's control went as far as even burning his leg to stop him smoking cigarettes.

Similarly another young boy, 17 years old, experienced difficult relationships with his father which finally led to him attempting suicide. These kinds of quarrel occurred from about a few months ago. I worked with him but it was very strict. Now I can't carry on and I am very tired (psychologically). My father usually let me use his car but for a few days he prevented me using it (Interviewee 7).

\section{Sibling conflicts}

One of the main subthemes emerged was sibling friction. Various reasons caused arguments and conflicts between siblings presented as gender roles, discrimination among siblings and bullying.

As pointed out by a young girl, her father and brother opposed her education, believing that her family and social role does not require such education. Their hostility towards her led her to set herself on fire. They told me that my education was not useful because in the end I had to get married, and that my future job was not more than a housewife. During my examinations when I had to concentrate on my lessons, they disturbed me intentionally (Interviewee 8).

Feeling discriminated against by siblings appeared to cause conflicts; this was highlighted by 2 young girls as the reason for frustration and attempting suicide. When I told my mum about our quarrel, she always said because I was the older one, I shouldn't have quarrelled with him. That's the reason why my brother is quarrelling with me. He often thinks he is not doing wrong (Interviewee 1). If I find any problem and argue with my younger brother, my parents take his side... I intend to kill myself because this situation is really intolerable for me (Interviewee 8).
Discrimination between girls and boys still seems to be a significant problem within traditional Iranian families.

A 15-year-old boy was bullied and physically abused by his older brother. He felt unprotected and extremely uncomfortable at home. He finally resorted to setting himself on fire to escape from hishorrible situation: I have problems with my elder brother. He usually falls in quarrel with me and beats me extremely. I cannot do anything against him ... He thinks I am a servantfor him (Interviewee 10).

\section{Pressure of high expectations}

Another major theme identified from data was pressure of high expectations from family and peer groups.

\section{Family pressures}

The data showed that some participants had felt extreme pressure from the family to achieve high standing in their education. Studying in high quality schools is considered socially prestigious for both students and their parents.

One young girl attempted suicide by overdose as a result of pressures from her mother to do better at school. She complained about her mother: My mum insisted that I register in a high quality school. I registered but I was unable to pass 3 subjects (Interviewee 3). She failed 2 consecutive years in that school and was finally forced to register in an evening school. She states: I tried to register with another [day] school but they did not accept me because of my [low] scores. Finally I had to attend evening classes. She felt very embarrassed and pressured from her mother who compared her poor performance with her high-achieving nieces. My cousins pay attention [work hard] in their lessons and studies. Once when they were in our house, my mum told them about my friends. She said that they sometime invited me to their homes for studying but that they don't study. I didn't like my mother speaking against me while my cousins were in our house. It was shameful and embarrassing for me (Interviewee 3).

A similar issue was raised by a young boy, 15 years old, who was living with 
his family in an outlying village in the south-western region of the country. His father was a builder. He had 4 brothers and sisters and was the third child of his family. One of his elder brothers was a soldier and the other one was unemployed. Owing to his family's low economic situation, his father expected him to do well in his studies so he could help the family in the future. He set himself on fire since he could not bear the pressure of not meeting his family's expectations: I had to pass all my exams and I had to revise the lessons for which I did not get the average mark. I am scared of my family, especially of my dad. My family expected me to be better in my studies (Interviewee 2).

\section{Peer pressure}

Pressure from peer groups was also highlighted by participants. The pressure and grief felt by one girl from her classmates as a result of her poor school performance led her to attempt suicide. I am so weak in education. I usually have Ghamo Ghoseh (grief) with my studies and my low position at school. My classmates underestimate me for this reason (I mean weak in education). I have a very hard time at school (Interviewee 18).

\section{Poverty}

Although economic hardships and unemployment were implicit in accounts made by many participants, this was explicitly highlighted by a young girl who also lost her mother 2 years previously. She believed that by killing herself she would ease the financial burden on family. She attempted suicide by overdosing on tablets; she says: I am living with my family. My family is big. We are 7 sisters and brothers. My father does not have a skilled job. He is a manual worker and his wage is too low. His income is so low that he can not support us.... Last night, when I realized my father had no money to buy food I became so Narahat [sad]. We slept while all of my sisters and my brothers were hungry. I thought the best way to reduce some of the family expenses would be the removal of family members. Therefore, I thought by taking my own life my family's difficulties would be eased (Interviewee 21).

\section{Discussion}

Our findings showed that many participants were on the verge of a psychoemotional breakdown. They commonly used culturally-bound terms to explain and express their psycho-emotional conditions. Words such as Narahati [not being comfortable, being upset or in distress], Assabani, Assabi, Feshareassabi, Assabe-e Khord [nervous, uncontrollable anger, being irritable, agitated, high temper, psychic pressure, and loss of self-control], $\mathrm{Na}$ omidi [hopelessness, futility, loss of hope], Zood-ranj [irritable or sensitive] were shared by many participants to position themselves in a culturally defined emotional mood. Good et al. also highlight the cultural influence on understanding and presentation of psychological disorder in the Islamic Republic of Iran [23].

In line with what has already been published, it could be argued that many participants resorted to attempting suicide as a cry for help [18], as an appeal [17] or to communicate with their parents, relatives and significant others $[24,25]$ in order to deal with their psycho-emotional despair. Youths tried to reduce social and family pressures, and overcome opposition to their will.

Although participants shared a common psycho-emotional despair, a variety of social, personal and family conflicts drove them towards this state. Our findings confirm previous studies in the Islamic Republic of Iran and elsewhere that family problems and failure in love are the most common reasons for attempting suicide [26,27]. The findings also agree with studies indicating that financial problems, unemployment and poverty contribute in attempted suicide in southern $[28,29]$ and western regions of the country [30]. Similar studies in Muslim countries highlighted family problems, interpersonal relationships (mainly with the opposite sex), unemployment and school performance as causes of attempted suicide [31,32].

Shame (Sharmmandegy or Khejalat) stems from the subject's feeling of general failure [17]. In agreement with the mainstream literature [32], we also found that social stigma and shame play an important role in attempted suicide among youth. Relationships between the opposite sexes outside marriage do exist in the Islamic Republic of Iran, but are considered an area of shame and stigma for the individual as well as the family. Our participants had fears regarding the social and family consequences of their love affairs being exposed. This stigma and shame also extended to other socially unacceptable behaviours such as teenage smoking.

Previous studies suggest that the family is an influencing factor in attempting suicide [33-35]. Despite dramatic sociocultural changes which have occurred in the Islamic Republic of Iran, the family institution still plays as important role in society. Strong family ties provide a great deal of support for family members in times of hardship. On the other, hand such close ties can potentially cause conflicts and problems between family members. Our findings showed that, although youth were enjoying family support, there were concerns about losing autonomy and self-determination. Family and social traditions and values sometimes impeded their choice in marriage. These traditions impose rules on issues such as marriage portion, social class and wealth of the partners, and marriage ceremonies, which could result in extreme difficulties and psychological pressures on youth, leading them to attempt suicide.

Another issue is that, owing to the high level of family support, children normally live with their parents until getting married. This increases the chance of conflicts and rivalry developing between siblings. 
Nowadays in the Islamic Republic of Iran, education is considered one the main factors in defining social class and prestige as well as conferring the prospect of achieving high social standing and status for both students and their parents. Many families put pressure on youth to do better in their education or pursue the dreams of their parents despite their own wishes. This pressure also comes from peers, the educational institutions and broader society. These extreme pressures could potentially cause youth to lose their self-esteem and result in suicide in order to escape from such pressure.

In agreement with international studies [36-38], our findings showed that poverty also contributes to suicide attempts among participants. Economic hardships and high unemployment in the Islamic Republic of Iran could cause effects within the family institution such as parental or sibling conflict as well as psycho-emotional distress in youth.

The findings of this study are in agreement with the mainstream literature on youth suicide in terms of the role of family problems, love, family and social pressures and poverty in attempting suicide. However, the contributing factors might have played out differently in our country compared to some other societies. The authors believe that the issue of social stigma, especially topics related to gender relationships and marriage, might be different from similar issues in "western" societies.
The findings of this study expand the conceptual and theoretical literature on suicide, particularly among youth. They could be used by policy makers and health care providers in designing and implementing effective suicide prevention programmes as well as providing better care for young people who attempt suicide. Health and medical education will benefit from the findings of this research through providing context-related material in training health professionals.

There were a few limitations to our study. Owing to the stigma related to issues such as suicide, it is possible that participants have not exposed the full reasons behind their suicide attempt. However efforts were made to overcome this limitation through establishing trust and rapport during interviews. The qualitative nature of the study limits its generalizability to the broader population. However, efforts made to enhance the representation of different voices and concerns of different participants in order to increase the credibility of data. Translation of data from Farsi to English might have contributed to partial distortion or loss of meanings of participant accounts. This limitation was minimized through translation and back translation of transcripts by the research team.

\section{Conclusion}

We investigated a range of different but interconnected contexts of suicide in Iranian youths. Understanding the sociocultural aspects of suicide is critical in providing effective and culturallysensitive suicide prevention and care programs. The family was considered the most important institution in young peoples' lives. This is where they are supported when facing social, cultural, and economic problems, and hence where a whole range of personal, social, cultural and economic problems could come together. In addition, there are other problems that especially affect young individuals: these are associated with social changes and the conflicts between traditional and modern attitudes such as pressure to succeed in education, desire for independent life and freedom in romantic affairs. Suicide prevention and care provision should devise a holistic approach taking into account medical as well as social, cultural and family factors in their assessment and care provision.

\section{Acknowledgements}

We would like to extend our gratitude to all the interviewees who kindly agreed to share their experiences, feelings, attitudes and information with us. This project was funded by the Social Sciences and Health Research Centre (SSHRC) affiliated to the Faculty of Health Management and Medical Informatics, Isfahan University of Medical Sciences. We also wish to thank Dr William Watts Miller for his support, guidance, comments and encouragement throughout this work.

\section{References}

1. De Wilde EJ. Adolescent suicidal behaviour: a general population perspective. In: Hawton K et al., eds. Suicide and attempted suicide. London, Wiley, 2000:249-259.

2. Coggan CA et al. Directory of Service for Youth Suicide. Auckland, Injury Prevention Research Centre, 1995.

3. Kachur SP et al. Suicide: epidemiology, prevention, treatment. In: Runyan $\mathrm{C}$ et al., eds. Adolescent medicine: state of the art reviews. Philadelphia, Hanley and Belfus, 1995.
4. Suicide prevention (SUPRE). Geneva, World Health Organization, 2006 (http://www.who.int/mental_health/prevention/ suicide/, accessed 20 April 2011).

5. Khan MM et al. Suicide in the developing world: case study from Pakistan. Suicide and Life-Threatening Behaviour, 2006, 36(1):76-81.

6. Ghoreishi SA et al. Systematic review of researches on suicide and suicide attempt in Iran. Iranian Journal of Psychiatry and Clinical psychology, 2008, 14:115-121. 
7. Abdollahi M et al. A retrospective study of poisoning in Tehran. Journal of Toxicology - Clinical Toxicology, 1997, I 35:387-339.

8. Ghazi-Khansari $M$ et al. A prospective study of fatal outcomes of poisoning in Tehran. Veterinary and Human Toxicology,1995, 37(5):449-455.

9. Ghadierifaraz B. [Estimate of the frequency of suicidal attempts by burning in the women patients in the hospital during the period 1999 and comparison with some of the individua characteristics in Department of Medicine] [MD dissertation] Isfahan, Isfahan University of Medical Sciences, 2000 [in Farsi; English abstract].

10. Durkheim E. Suicide: a study in sociology. London, Routledge, 1952

11. Erkki T et al. Suicide in major depression. American Journal of Psychiatry, 1994, 151:530-536.

12. Pritchard C. Is there a link between suicide in young men and unemployment? A comparison of the UK with other European Community countries. British Journal of Psychiatry, 1992, 160:50-56

13. Platt S. Unemployment and suicidal behaviour: a review of the literature. Social Science \& Medicine, 1994, 19:93-115.

14. Taylor R et al. Suicide in Urban New South Wales, Australia 1985-1994: socio-economic and migrant Interactions. Social Science \& Medicine, 1998, 47:1677-1686.

15. Lester D. Suicide and Islam. Achieves of Suicide Research, 2006, 10(1):77-97.

16. Douglas J. The social meaning of suicide, Princeton, New Jersey, Princeton University Press, 1967.

17. Baechler J. Suicide. Oxford, Basil Blackwell, 1979.

18. Taylor S. Durkheim and the study of suicide, London, Macmillian Press, 1982.

19. Silverman D. Interpreting qualitative data: methods for analysing talk, text and interaction, 2nd ed. London, Sage, 2004.

20. Green J et al. Qualitative methods for health research. London, Sage, 2004.

21. Rubin $\mathrm{H}$ et al. Qualitative interviewing: the art of hearing data, 2nd ed. London, Sage, 2005.

22. Sandelowski M. Qualitative analysis: what it is and how to begin. Research in Nursing and Health, 1995, 18(4):371-375.

23. Good B et al. The interpretation of Iranian illness and dysphoric affect. In: Kleinman A et al., eds. Culture and depression: studies in the anthropology and cross-cultural psychiatry of affect and disorder. Berkeley, Los Angeles, University of California Press, 1985:369-428.

24. Stengel E. Suicide and attempted suicide. Harmondsworth, Penguin, 1973.

25. Hods M. Overdosing as communication: a cultural perspective. British Journal of Medical Psychology, 1990, 63:319-333.

26. Mohammadi MR et al. Suicidal attempt and psychiatric disorders in Iran. Suicide and Life-Threatening Behaviour, 2005, 35(3):390.

27. Headley LA. Suicide in Asia and the Near East. California, University of California Press, 1983, 238-257.

28. Janghorbani $M$ et al. Completed and attempted suicide in Ilam, Iran (1995-2002): increase and associated factors. Archives of Iranian Medicine, 2005, 8(2):199-129.

29. Toobaei $\mathrm{SH}$ et al. Suicidal causes among 15 to 30 year olds in Shiraz, Southern Iran. Iranian Journal of Medical Sciences, 1999, 24(1\&2):14-19.

30. Mofidi $\mathrm{N}$ et al. Attitudes towards suicide among Kurdish people in Iran. Social Psychiatry and Psychiatric Epidemiology, 2008, 43:291-298.

31. Al Ansari A et al. Risk factors associated with overdose among Bahraini youth. Suicide and Life-Threatening Behaviour, 2001, 31(2):197.

32. Dabbagh TN. Parasuicide in Arab Palestinian society of the West Bank [Doctoral thesis]. London, Department of Psychiatry, University College, 2000.

33. Adams DA et al. Perceived family functioning and adolescent suicidal behavior. Journal of the American Academy of Child and Adolescent Psychiatry, 1994, 33:498-507.

34. Besnard P. Marriage and suicide: testing the Durkheimian theory of martial regulation a century later. In:. Pickering W et al., eds. Durkheim's suicide: a century of research and debate. London, Routledge, 2000.

35. McDermut $W$ et al. Family functioning and suicidality in depressed adults. Comprehensive Psychiatry, 2001, 42(2):96-104.

36. Crawford MJ et al. Increasing rates of suicide in young men in England during the 1980s: the importance of social context. Social Sciences \& Medicine, 1999, 49:1419-1423.

37. Platt S. Parasuicide and unemployment. British Journal of Psychiatry, 1986, 149:401-405.

38. Platt $\mathrm{S}$ et al. Suicide behaviour and the laubour market. In: Hawton $\mathrm{K}$ et al., eds. The international handbook of suicide and suicide behaviour. New York, Wiley, 2000:310-384. 